BNWL-SA-5296

INFLUENCE OF INHALED Ca-DTPA ON THE LONG-TERM EFFECTS OF INHALED PU NITRATE

by J. E. Ballou, G. E. Dagle, K. E. McDonald and R. L. Buschbom

Battelle

Battelle Northwest Laboratory

Richland, Washington 99352

This report was prepOTICE an account of work

sponsored by the United States Government. Neither

the United States nor the United - States Energy Research and Development Administration, nor any or

their employees, nor any employees, makes any

subcrinty, express or implied, or assumes any legal

liability or responsibility for the accuracy, completeriess

or usefulness of any information, apparatus, product or

process disclosed, or represents that its use would no

infringe privately owned rights.

* This paper is based on work performed under U. S. Energy Research and Development Administration Contract No. AT(45-1):1830 


\section{DISCLAIMER}

This report was prepared as an account of work sponsored by an agency of the United States Government. Neither the United States Government nor any agency Thereof, nor any of their employees, makes any warranty, express or implied, or assumes any legal liability or responsibility for the accuracy, completeness, or usefulness of any information, apparatus, product, or process disclosed, or represents that its use would not infringe privately owned rights. Reference herein to any specific commercial product, process, or service by trade name, trademark, manufacturer, or otherwise does not necessarily constitute or imply its endorsement, recommendation, or favoring by the United States Government or any agency thereof. The views and opinions of authors expressed herein do not necessarily state or reflect those of the United States Government or any agency thereof. 


\section{DISCLAIMER}

Portions of this document may be illegible in electronic image products. Images are produced from the best available original document. 


\title{
Influence of Inhaled Ca-DTPA on the Long-Term Effects of Inhaled Pu Nitrate
}

J. E. Ballou, G. E. Dagle, K. E. McDonald and R. L. Buschbom

\author{
Biology Department \\ Battelle \\ Pacific Northwest Laboratories \\ Richland, WA 99352
}

\section{Introduction}

The calcium salt of the chelating agent diethylenetriaminepentaacetic acid (Ca-DTPA) is the recognized drug for use in decorporation therapy for deposited plutonium. The recommended dosage regimen employs repeated daily administration of 1 gram Ca-DTPA by intravenous drip. Within the last decade or so the chelating agent has also been administered by the inhalation route since this drug is readily absorbed from the lung and inhalation avoids the trauma of injection as well as expedites the early administration of treatment without the necessity for hospitalization. Very little is known about the toxicology of inhaled Ca-DTPA except through inference from a number of studies of the toxicity following other routes of administration. We have found at $\mathrm{BNW}$ that rats tolerate intratracheally instilled Ca-DTPA quite well with only minimal histopathological effects at dose levels 10 to 15 times greater than the dose administered by inhalation to humans. Intratracheal doses 20 to 30 times greater than the human therapeutic dose induced a transient alveolar cell metaplasia that recovered within 2 weeks after treatment. Since similar metaplastic

This work was done by Battelle, Pacific Northwest Laboratories, for the U. S. Atomic Energy Commission under Contract AT(45-1)-1830. 
changes in the alveolar epithelium are associated with early stages in the process of plutonium damage in the lung it is of interest to investigate the possible additive effect of inhaled Ca-DTPA on the development and progress of these lesions. This paper reports results in rats exposed to aerosolized Ca-DTPA administered 20 days after inhalation of Pu nitrate. Chelate treatment was delayed to lessen the efficiency of decorporation thus increasing the possibility of detecting an effect that could be attributed to Ca-DTPA toxicity. Changes in weight gain, mortality and the incidence of malignant lung and bone tumors were observed for the animals life-span.

\section{Methods}

Male Wistar rats were employed in this study, exposed to plutonium nitrate or Ca-DTPA aerosols as indicated in the experimental protocol in Table 1. Sham treatment consisted of simulated exposure to Ca-DTPA, i.e. animals were confined in individual animal holders and placed in the exposure chamber for the sallie time period without gencrating an aerosol. The plutonium aerosols were generated with a Lovelace nebulizer employing a $0.27 \mathrm{~N}$ nitric acid solution containing $70 \mu \mathrm{Ci}{ }^{239} \mathrm{Pu} / \mathrm{mT}$. The rats were exposed to a chamber concentration of $88 \mathrm{nCi} / 1$, particle size was 1.043 AMAD with a GSD of 1.730. The rats were exposed nose only for 1 hour and were then housed in a filtered holding box for 7 days before being transferred to the regular small animal quarters. Ten rats were sacrificed immediately after exposure to determine the initial lung burden (ILB $=78$ $\mathrm{nCi}$, range 51-105 $\mathrm{nCi}$ ). Additional animals were sacrificed after 30,60, 
100 and 150 days to determine lung clearance kinetics and the distribution pattern of plutonium translocated from the lung. Twenty days after plutonium exposure 58 rats were selected for Ca-DTPA treatment and 28 were selected for sham exposure. Chelate treatments and sham exposures lasted for 1 hour and were repeated at weekly intervals for a total of six treatments. Additional animals were exposed to Ca-DTPA aerosols (70 rats) or sham Ca-DTPA (30 rats) following the same treatment regimen. A group of 99 nontreated control animals completed the study.

The chelate aerosols were generated from a $25 \%$ solution of Ca-DTPA in water employing a Retec nebulizer. The chamber concentration was $3.5 \mathrm{mg}$ DTPA/1, the particle size was $4.3 \mu \mathrm{m}$ MMAD with a GSD of 2.22. The effective absorbed DTPA dose was approximately $3 \mathrm{mg} /$ rat/treatment. The absorbed dose was assumed to equal that amount of DTPA recovered in urine the first 3 days after DTPA treatment. This dose $(7 \mathrm{mg} / \mathrm{kg})$ approximates the human therapeutic dose on a per-kilogram basis assuming about $50 \%$ of the drug is absorbed during human inhalation therapy.

DTPA was analyzed by the method of Wallace and Hinton published in Anal Chim Acta 51: 536-538 (1970). The method is based on the formation of the Fe-DTPA chelate which can pass through a cation exchange column. whereafter $\mathrm{Fe}$ is determined by atomic absorption analysis and the amount of OTPA is determined indirectly assuming a 1:1 molar complex for Fe-DTPA. In our hands the method was satisfactory for analyzing aerosol samples or other fairly pure solutions of DTPA: In biological fluids such as urine however, a fairly large and variable background correction was required to account for what appeared to be a natural chelating substance that also 
carried Fe through the resin column and led to spuriously high values for DTPA absorption. An alternate method for estimating Ca-DTPA dose based on respiratory parameters and aerosol characteristics suggests a dose of 5 $\mathrm{mg} / \mathrm{rat} /$ treatment in reasonable agreement with the value determined from urine analysis.

The rats were held for life-span study of the long-term biological effects of plutonium and Ca-DTPA treatment. Each group was weighed at monthly intervals and examined daily for dead or moribund animals. Animals found dead or sacrificed were subjected to detailed necropsy where 8 major organs and ail suspicious lesions were sectioned for histopathologic examination. Where appropriate, tissues were analyzed for plutonium content (lung, skeleton, liver, tracheobronchial. lymph nodes, pelt and residual soft tissues) using the extraction and liquid scintillation technique of Keough and Powers (1970).

Radiation dose to lung and skeleton was calculated for each plutonium rat using clearance parameters determined from the retention of plutonium in animals which died during the course of the experiment as well as those sacrificed specifically to determine retention kinetics. Retention in lung was best described by the sum of 3 exponential functions (Figure 1) while plutonium retention in skeleton was assumed to remain unchanged throughout the animals life-span (Figure 2).

\section{Results \& Discussion}

Inhalation of $\mathrm{Pu}\left(\mathrm{NO}_{3}\right)_{4}$ or Ca-DTPA at the dose levels employed in this study did not influence weight gain (Figure 3) or time of death (Figure 4) 
as compared to the nontreated controls. It is also apparent that the incidence Qf lung tumors and bone tumors was not significantly different in the treated and nontreated plutonium rats (Table 2). Ca-DTPA did, however, decrease the amount of plutonium in the skeleton by about $20 \%(p=0.05)$ and the 1 ung burden was marginally decreased $(p=0.1)$. The decrease in plutonium burden wạs apparently not sufficient to deter the induction of tumors or at least the effect was not detectable in this study. 'Since the initial deposition of plutonium ranged from 50 to $150 \mathrm{nCi}$ in these rats the marginal effects of therapy could not possibly be seen over this background of variability. After 614 days the skeleton showed a similar 3-fold range in plutonium burden further illustrating the difficulties involved in demonstrating a statistically significant effect of treatment.

Variations in the initial lung burden combined with differences in life span resulted in a wide range of radiation dose accumulated by the lung and skeleton in both treatment groups. The dose to lung ranged from 36 to 2000 rads (Table 3). The lowest dose which induced a lung tumor was 50-60 rads accumulated over 600-900 days. The highest dose to produce a lung tumor was 2000 rads accumulated over 975 days. A single lung tumor was found in a rat exposed only to Ca-DTPA and no malignant lung tumors were seen in the nontreated controls. The single tumor with Ca-DTPA can not be assumed to be significant in this study al though the normal incidence of malignant lung tumors is known to be quite low in the Wistar strain.

The dose to skeleton was an order of magnitude lower than the lung dose (Table 4) and the number of tumors correspondingly less. Only two 
osteosarcomas were found, one in each group appearing after about 10 rads. and 25 rads accumulated dose to skeleton. Since the dose calculation assumed no loss of plutonium from skeleton during the animals life time the cumulative rad dose may be low by as much as a factor of 2 if, for example, the retention half-time was 500 days as has been reported in some studies. The low incidence of bone tumors is typical of other studies with inhaled plutonium where similar bone doses were accrued.

\section{Conclusions}

Inhaled Ca-DTPA administered to rats in 6 , weekly, one-hour treatments of $3 \mathrm{mg} / \mathrm{rat}$ did not effect weight gain or life-span compared to plutonium burdened animals (78 $\mathrm{nCi}$ ILB) or nontreated controls. In addition, the drug did not appear to promote the development of malignant lung tumors and bone tumors in plutonium burdened rats although one rat exposed only to Ca-DTPA aerosols did develop a malignant lung tumor. This single lung tumor can not be considered significant although the normal incidence of this lesion is quite low. Inhaled Ca-DTPA therapy administered 20 days after plutonium inhalation showed little effect in reducing the lung burden of plutonium. Skeletal deposition was decreased possibly because Ca-DTPA was administered during a time of active translocation of the inhaled plutonium when plutonium may have been available for chelation in the blood. Inhaled Ca-DTPA therapy did not appear to be beneficial in reducing the number of malignant lung tumors or bone tumors in plutonium burdened rats but on the other hand the chelate did not appear to promote these lesions. 
Table 1

\section{Experimental Protocol}

\begin{tabular}{|c|c|}
\hline Treatment & $\begin{array}{l}\text { Number } \\
\text { of Rats }\end{array}$ \\
\hline $\mathrm{Pu}\left(\mathrm{NO}_{3}\right)_{4}+$ Sham Ca-DTPA & $28(8)^{\star}$ \\
\hline $\mathrm{Pu}\left(\mathrm{NO}_{3}\right)_{4}+\mathrm{Ca}-\mathrm{DTPA}$ & $58(12)$ \\
\hline Sham Ca-DTPA & 30 \\
\hline Ca-DTPA & 70 \\
\hline Nontreated Controls & 100 \\
\hline
\end{tabular}

*Values in parenthesis are number of rats sacrificed to determine efficacy of Ca-DTPA. 
Table 2

Summary of Long-Term Effects

\begin{tabular}{|c|c|c|}
\hline & \multicolumn{2}{|c|}{ Tumor Incidence (\%) } \\
\hline Treatment & Lung & Bone \\
\hline $\mathrm{Pu}\left(\mathrm{NO}_{3}\right)_{4}+$ Sham Ca-DTPA & 47 & 5.3 \\
\hline $\mathrm{Pu}\left(\mathrm{NO}_{3}\right)_{4}+\mathrm{Ca}-\mathrm{DTPA}$ & 42 & 2.3 \\
\hline Sham Ca-DTPA & 0 & 0 \\
\hline Ca-DTPA & .1 .4 & 0 \\
\hline Nontreated Controls & 0 & 0 \\
\hline
\end{tabular}


Table 3

$\mathrm{Pu}\left(\mathrm{NO}_{3}\right)_{4}$ Induced Lung Tumors

- Effect of Inhaled Ca-DTPA -

\begin{tabular}{|c|c|c|c|}
\hline $\begin{array}{c}\text { Dose Range } \\
\text { (Rads) } \\
\end{array}$ & $\begin{array}{l}\text { Number } \\
\text { of Rats }\end{array}$ & $\begin{array}{c}\text { Days at } \\
\text { Risk (Ave.) } \\
\end{array}$ & $\begin{array}{l}\text { Rats with } \\
\text { Lung Tumors }\end{array}$ \\
\hline $36-100$ & $5(1) *$ & $603(888)$ & $1(1)$ \\
\hline $101-300$ & $13(3)$ & $555(546)$ & $5(1)$ \\
\hline $301-500$ & $16(7)$ & $657(608)$ & $5(3)$ \\
\hline $501-1000$ & $8(5)$. & $714(699)$ & $6(2)$ \\
\hline $1001-2000$ & $7(3)$ & $975(641)$ & $1(2)$ \\
\hline Ca-DTPA & $70(30)$ & $604(591)$ & $1(0)$ \\
\hline Control & 99 & 677 & 0 \\
\hline
\end{tabular}

* Values in parenthesis are for animals given sham Ca-DTPA exposure. 
Table 4

$\mathrm{Pu}\left(\mathrm{NO}_{3}\right)_{4}$ Induced Bone Tumors

- Effect of Inhaled Ca-DTPA -

\begin{tabular}{|c|c|c|c|}
\hline $\begin{array}{c}\text { Dose Range } \\
\text { (Rads) }\end{array}$ & $\begin{array}{l}\text { Number } \\
\text { of Rats }\end{array}$ & $\begin{array}{c}\text { Days at } \\
\text { Risk (Ave.) }\end{array}$ & $\begin{array}{l}\text { Rats with } \\
\text { Bone Tumors } \\
\end{array}$ \\
\hline $2-10$ & $17(0) *$ & $470(\cdot 0)$ & $1(0)$ \\
\hline $11-20$ & $11(6)$ & $586(593)$ & $0(0)$ \\
\hline $21-30$ & $5(2)$ & $692(680)$ & $0(1)$ \\
\hline $37-78$ & $7(10)$ & $733(653)$ & $0(0)$. \\
\hline Ca-DTPA & $70(30)$ & $604(591)$ & $0(0)$ \\
\hline Control & 99 & 677 & 0 \\
\hline
\end{tabular}

*Values in parenthesis are for animals given sham Ca-DTPA exposure. 


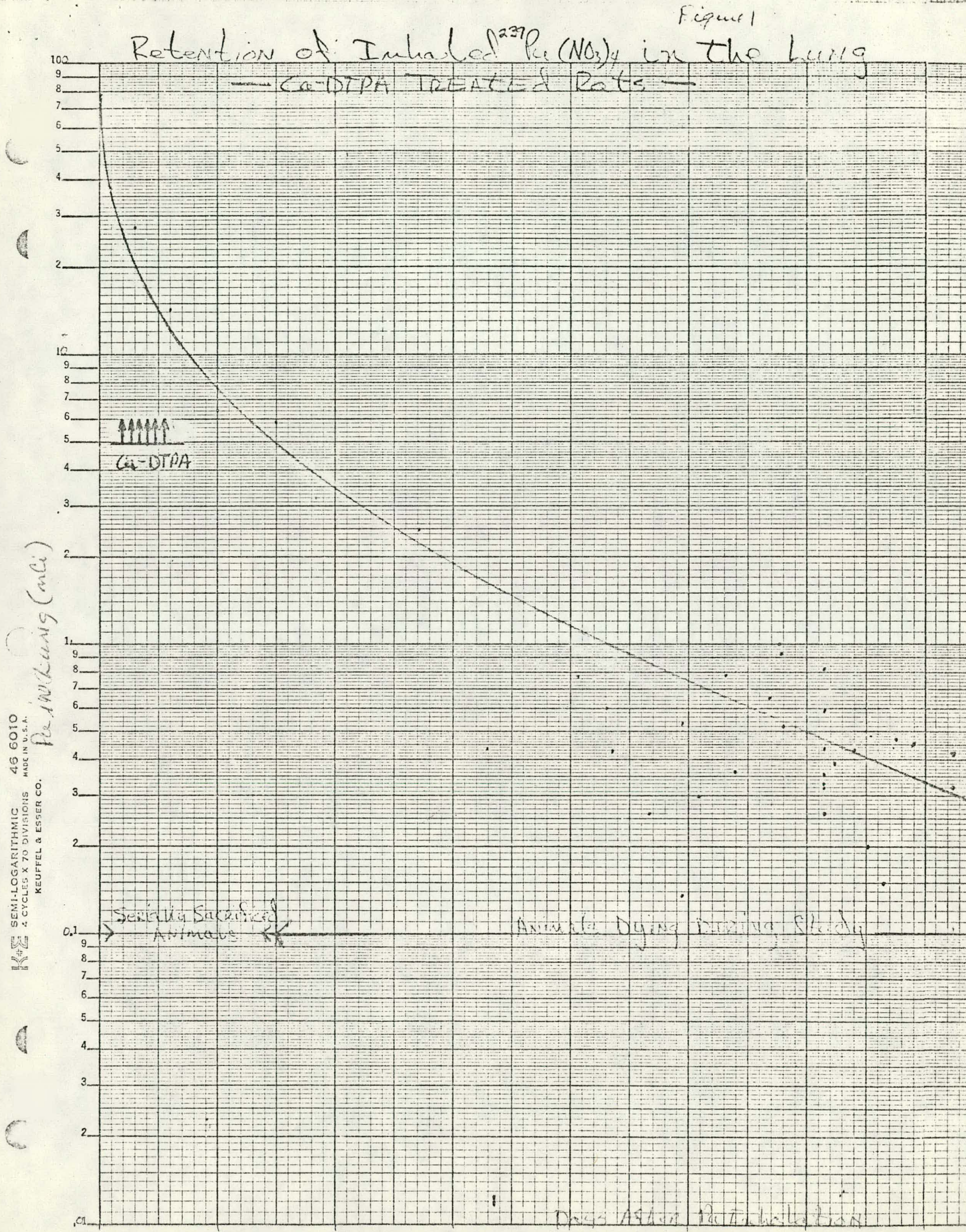




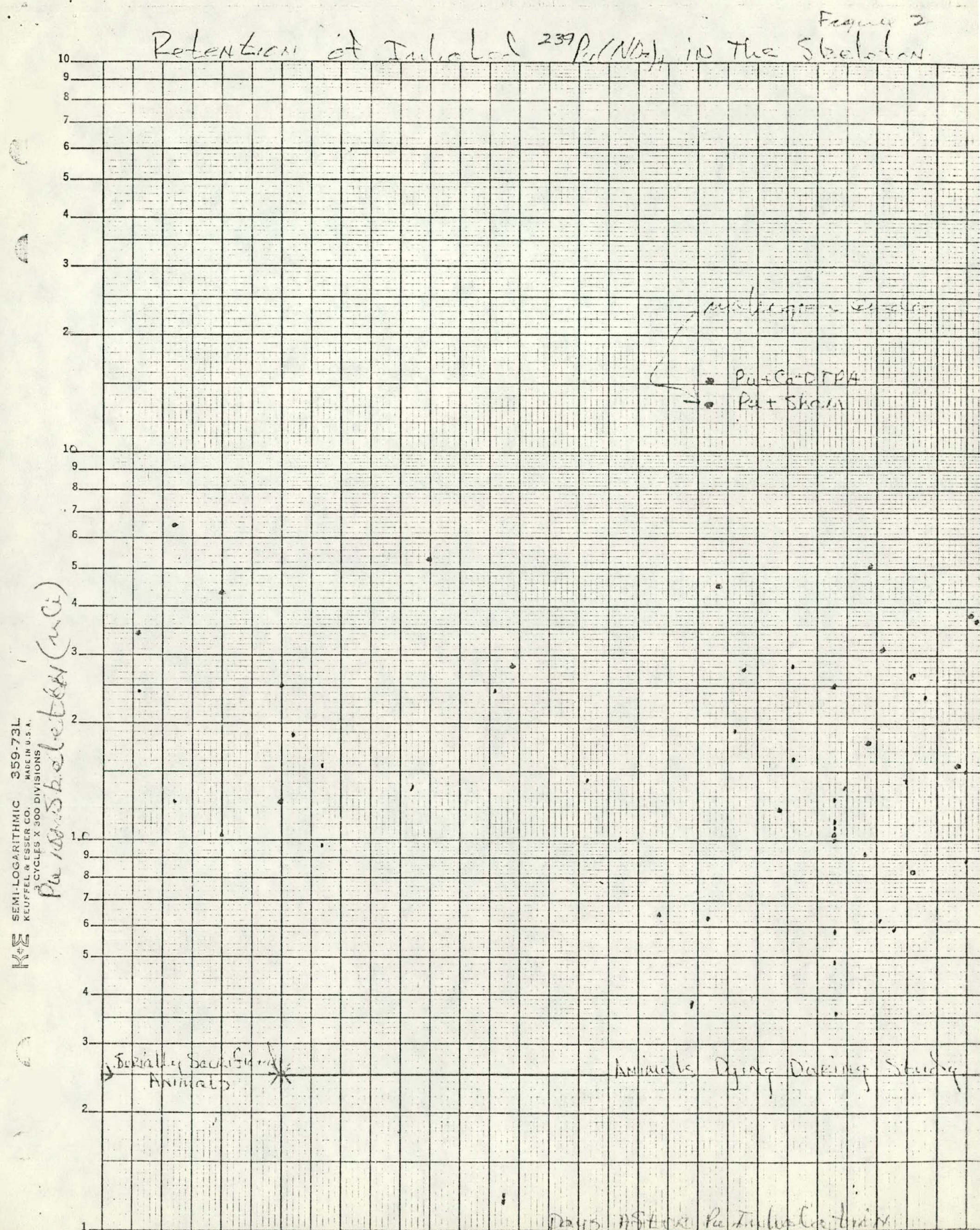


Fegwe 3

Effoct of Fubad Co-DTPA on spoipht Gain

$\Delta \operatorname{con} \quad \alpha$

- fac yt ca-ding

- Pu(No) +Sham 1.

- Ca-DTPA

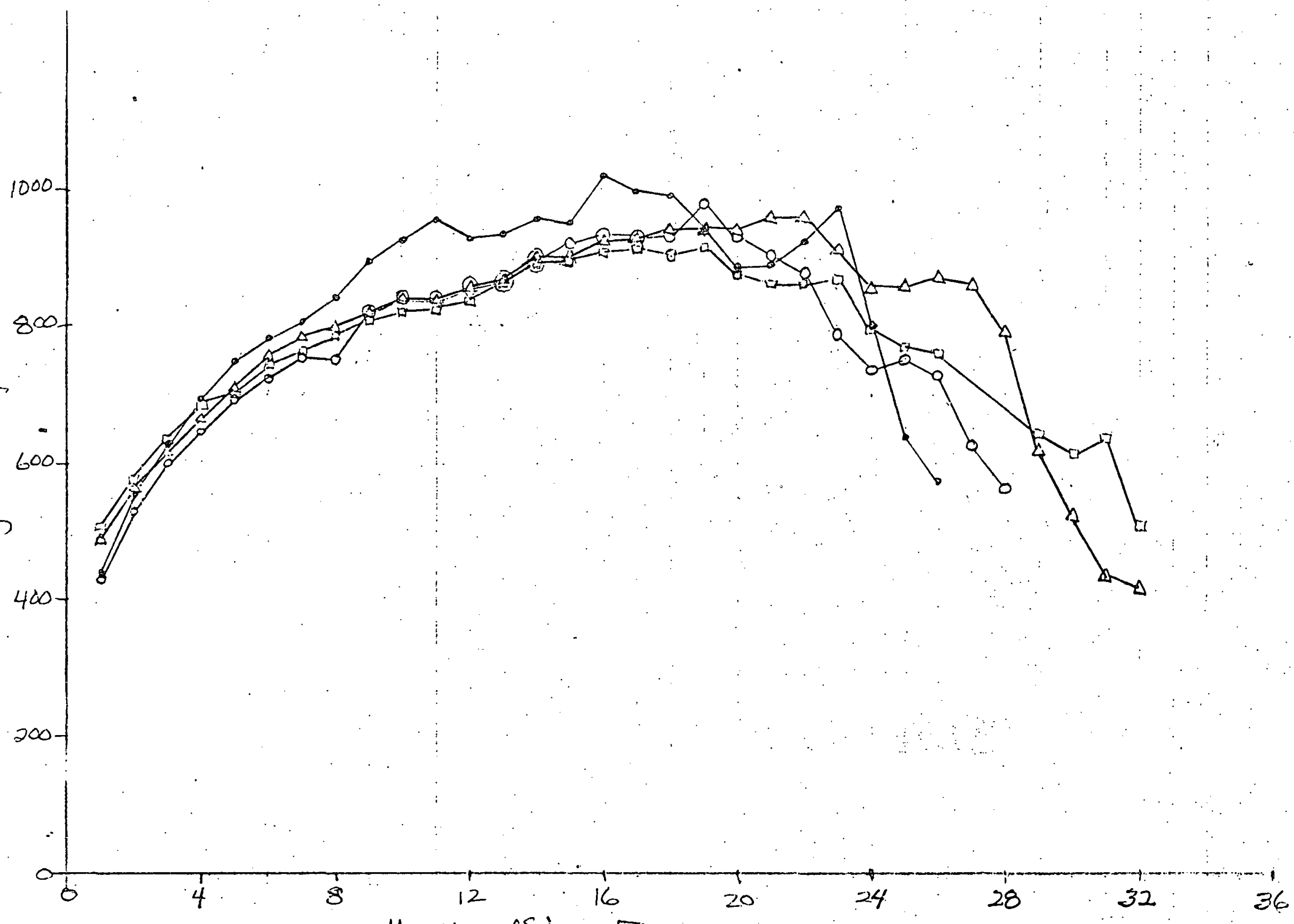

Months After Exposure 
Effet of Inhald Ca-DTHA on Susviral

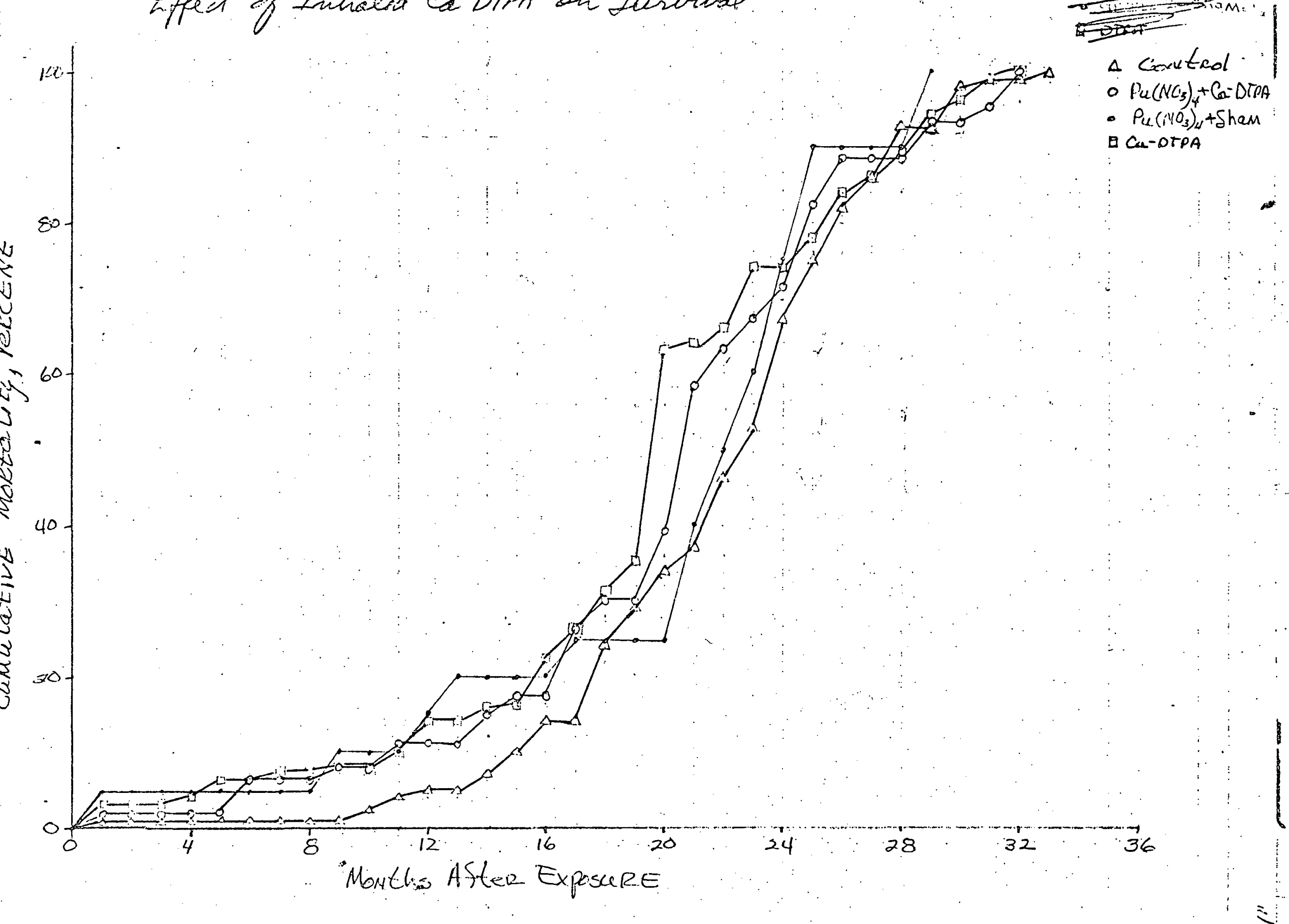

